d'autres issues du corps, qu'on regarde comme impures et souillées" (Pierre Gonnerat, "Voyage aux Indes Orientales et à la Chine," à Paris, 1782, vol. i., p. 93). Kumagusu Minakata.

Tanabe, Kii, Japan, December I3, r9i3.

\section{Systems of Rays on the Moon's Surface.}

A GREAT deal has been said, and a great many theories have been put forward, as to the cause of these marvellous systems of rays on the surface of the moon. I now venture to put forward an explanation which has occurred to me, and should like the opinion of some of your readers upon it.

It is generally admitted that the volcanic action of the moon was of an enormous character, "even when the low force of lunar gravity is taken into consideration," and from our knowledge of the amount of lava emitted from one of our own small craters, we can conceive what a huge volume must have been thrown out from such gigantic craters as Clavius, Ptolemäus, or Copernicus. Now, from what we can see even to-day, the lunar surface is exceedingly mountainous, and I suggest that when these craters were in their full power huge volumes of lava were thrown out, and in many cases practically filled up valleys, or cañons between the mountains. We know the rays are from five to ten miles broad, even up to twenty miles, and from the action of the volcano there would always be the tendency for the lava to run away from the crater itself, thus forming these rays, like spokes from a hub. Some of the rays are, however, apparently of a prodigious length, up to 2000 miles long, but Prof. Pickering tells us that this length is an illusion, the long rays being made up of rays from different craters, which appear to form one long continuous ray, which satisfies the question of length.

Then many of these rays apparently run right across and almost obliterate (at full moon) such craters as Clavius and Maginnus. Now I think it is generally admitted that the ray systems from Tycho, Copernicus, and Kepler are the largest on the moon, and they are also three of the very largest craters. This points to the fact that they were the first eruptions on the lunar surface, and being the first, threw out the greatest volume of lava. This filled up the valleys in their neighbourhood, but afterwards other craters were ercipted through the Iava-covered rocks, though without breaking up the "lava valleys." It is highly probable that in these circumstances most, or all, the craters have their rays, though too small to be detected through even the largest glass. Their brilliance would, of course, be accounted for, by the sun shining directly upon them, through no atmosphere at all, or none worth mentioning. It seems, therefore, to me, that these rays must be geologically old remains of eruptions, dried up now, but still showing themselves on the lunar surface, though it is doubtful if the matter will ever be satisfactorily cleared up. C. HUBERT PLANT.

49 Lichfield Road, Walsall, December 16, I913.

\section{THE CAPE OBSERVATORY.}

I $\mathrm{N}$ the preface to this work Sir David Gill relates that when, as a young astronomer, he was connected with Lord Crawford in the design and erection of the observatory at Dun Echt, he turned for assistance to Wilhelm Struve's "Description de l'Observatoire Astronomique Central

1 "A History and Desrriction of the Royal Observatory, Cape of Foor Hope." Ry Gir "avid rill K.C.R. F.R.S. Pp. cxc+136+plates. (London: H.M. Sta.i.nery Ofice, rgrs) NO. 2307 , VOL. 92] de Poulkova." Remembering the help and pleasure which Struve's work had given him, he resolved, in humble imitation, to write a description of the Cape Observatory.

"Struve," in the words of Gill, "had the true genius and spirit of the practical astronomer, the love of refined and precise methods of observation, and the inventive mechanical and engineering capacity."

Struve had the rare opportunity of building an observatory after his own heart, regardless of expense, which should fulfil the highest requirements of the astronomy of his time. Gill, animated by the same spirit as Struve, and with similar qualifications, greatly extended and remodelled an historic observatory. Thanks to his grasp of the trend of astronomy, his skill in the design and construction of instruments, and his administrative ability and energy, he left the Cape Observatory, at the close of his directorate, one of the best equipped and most efficient observatories in the world.

The volume, as its title indicates, is divided into two parts. The first consists of a history of the observatory from its foundation to the present time, with brief biographical notices of those who have filled the position of H.M. Astronomer, and an appreciative criticism of their work and their contribution to the development of the observatory. Following this is a brief account of the past and present instrumental equipment, and a comprehensive survey of the important astronomical and geodetic results which have proceeded from the Cape Observatory. The second part of the book is devoted to a detailed description, illustrated by many photographs and diagrams, of the important instruments which have been erected at the observatory during Sir David Gill's directorate.

The value of the Cape as a site for the extension of astronomy and geodesy to the southern hemisphere was first appreciated by Lacaille, who in a brief visit in the middle of the eighteenth century made observations of the positions of more than ro,ooo stars, and measured an arc of the meridian.

After the British occupation, the establishment of a permanent observatory at the Cape was considered by the Board of Longitude in February, I820; the appointment of an astronomer was recommended, and estimates were obtained from Troughton, Dollond, and Jones for suitable equipment. The Board of Admiralty expressed its concurrence with this proposal, and the observatory was established by Order in Council on October 20 , 1820 , the staff to consist of one astronomer, one assistant, and one labourer.

The Rev. Fearon Fallows, fellow of St. John's College, Cambridge, was appointed H.M. Astronomer, and directed to make observations so far as possible similar to and complementary to those at Greenwich. He fixed the site of the observatory on part of a bare, rocky hill, covered with thistles and infested with snakes, but tolerably free from the sandy dust prevalent near Cape Town, and commanding a good view of Table 
Bay, so that ships anchored there might be able to observe the time-signals. The order to commence building was signed in 1822 , but did not reach Fallows until 1825 . After a change of Government in 1827 , ro,oool. was cut off the estimates for building, so that when completed the observatory was a mere block of masonry on a desolate hill, without protection, an adequate water supply, or roads. The instruments were, however, installed, and some valuable observations made.

Fallows died in I83 I, after eleven years' work, full of anxiety and disappointment, and was succeeded by Henderson, who remained at the Cape only one year, but crowded into that time an enormous number of observations of various kinds. His most permanently valuable work is his catalogue of positions of the principal southern stars, obtained with similar accuracy to that of the northern stars at the same epoch, but his most striking discovery and that which his name invariably calls to mind, is his determination of the parallax of $\alpha$ Centauri.

Henderson's successor was Maclear. He remained director of the observatory from $1833-70$. Maclear was a man of great energy and practical ability. He faced the difficulties which had disheartened Fallows, and from which Henderson had shrunk, and succeeded in making the barren hillsides into fertile grounds, in obtaining a pure water supply, in breaking the force of the southeast winds by planting trees, and establishing a communication with the main road to Cape Town. At the same time the scientific work of the observatory was carried on untiringly, both with the meridian instruments and equatorials. Owing to the smallness of the staff, the observations were not all reduced and published at the time, but Maclear's successors, Stone and Gill, were able to publish these valuable observations. In addition, he found opportunities to extend help and infuse enthusiasm into the educational and scientific projects of the growing colony.

Maclear was succeeded by Stone. He had been trained at Greenwich in the systematic school of Airy, and left as a lasting monument of his nine years at the Cape (1870-79) a catalogue of 12,88I stars.

Gill was appointed H.M. Astronomer on February 19, I879, and retired on February 19, 1907, after completing twenty-eight years of service. At the University of Aberdeen he had the good fortune to come under the influence of Clerk Maxwell, and gain inspiration from his teaching. His interest in astronomy began with the installation of a time service for Aberdeen, which he carried out with the assistance of David Thomson, professor of natural philosophy. Shortly afterwards he purchased a I2-in. mirror, mounted it equatorially, and used it in measuring double stars, taking photographs of the moon and other observations. In 1872 he was offered charge of the observatory which Lord Lindsay was erecting at Dun Echt; he relinquished his business career, and accepted without hesitation the opportunity thus presented of devoting his whole time to science.

Gill now entered on the congenial task of assisting in the design and erection of Lord Lindsay's magnificent private observatory, and the testing, mounting, and adjustments of its numerous instruments. Soon afterwards he accompanied Lord Lindsay to Mauritius to observe the transit of Venus, and in this connection made several important determinations of longitude. In 1877 he made an expedition to Ascension, and from observations of Mars with a 4-in. heliometer, determined the solar parallax as $8^{\circ} 78^{\prime \prime}$, with a probable error of $\pm 0^{\circ}$ or $2^{\prime \prime}$.

Thus fitted by his training and experience, Gill found at the Cape Observatory ample scope for his energy and for his mechanical and observational skill. In 1879 the only instruments at the Cape were the non-reversible transit-circle, the 7 -in. equatorial, and the photoheliograph. During his tenure of office a 7 -in. heliometer, an astrographic equatorial of $I_{3}$ in., the Victoria telescope, presented by Mr. McClean, consisting of a 26-in. photographic telescope for spectroscopic work, with an r8-in. guiding telescope, and a new reversible meridian circle were all added to the equipment, and from all these instruments important results have already been obtained. With the non-reversible transit instrument observations of fundamental stars, bright southern stars, and stars the positions of which were required as comparison stars for heliometer observations were carried on systematically, and particular mention may be made of a catalogue of $865^{\circ}$ reference stars for the astrographic work at the Cape.

From the commencement of his tenure of office Gill urged the necessity of a reversible instrument for fundamental work. The project was not sanctioned, however, until r897. The greatest care was lavished on the instrument, the building and the foundations. The full description, occupying one hundred pages of the book, and illustrated by many photographs and drawings, cannot be summarised in a short review, and only a bare mention can be made of the most striking and interesting features. Besides being reversible, the object-glass and eye end of the instrument are interchangeable, so that flexure may be eliminated, except for the sagging of the wire, in the mean of opposite positions. The microscopes are carried on iron piers, which are covered externally by non-conducting material, and are filled with water so that their temperature may be uniform in horizontal layers, and no tendency to twist be introduced. To detect any shift of the telescope in azimuth, stable meridian marks are obtained by connecting optically the marks and collimator lenses $N$. and $S$. of the instrument, with points fixed on the solid rock at the bottom of deep iron cylinders. These have proved so successful that the movement of the pole in azimuth corresponding to the variation in latitude has been observed. The instrument is furnished with an impersonal micrometer for the elimination of magnitude equation from the observations of No. 2307 , vor. 927 
right ascension. To save the strain on the observer this is moved at approximately the right rate by an electric motor with suitable mechanism for giving the rate corresponding to the declination of the star. The great success of this instrument is attested by the results already published by Mr. Hough.

A full description is also given of the Victoria telescope, presented to the observatory by $\mathrm{Mr}$. Frank McClean. It is furnished with a spectroscope for the determination of velocity in the line of sight, and with two large objective prisms of 24 in. aperture and refracting angles of $8^{\circ}$ and $2^{\circ}$ respectively. These can be used singly or together. Excellent results, including a determination of the solar parallax by Dr. Halm, have been already obtained with the line of sight spectroscope. The Cape Observatory is therefore, thanks to the generosity of Mr. McClean, admirably equipped for astrophysical work.

While the reversible transit-circle and the Victoria telescope are probably the instruments which will be most valuable to Sir David Gill's successors, it is with the 7 -in. heliometer that most of his own personal observing work has been done. This instrument was obtained in 1887 to supersede the 4-in. used at Ascension. With it (partly in cooperation with Dr. Elkin) he made the well-known determinations of the parallax of the sun and of the brightest stars of the southern hemisphere, remarkable alike for the smallness of their accidental error and the care with which causes of systematic error were eliminated. In addition, the 7 -in. heliometer has been used in other important investigations, particularly in the determination of the mass of Jupiter and the orbits of its satellites, researches in which two young astronomers, Mr. Bryan Cookson and Mr. de Sitter cooperated.

Sir David Gill includes an account of the Cape Photographic Durchmusterung. Knowing that this survey of the southern sky was proposed, Prof. Kapteyn volunteered to undertake the arduous work of measuring the photographs and discussing the results. From this cooperation, a catalogue containing the magnitudes and approximate positions of 450 , 000 stars resulted, giving a complete survey of the southern skies; it is noted that the preparation of this work first directed Kapteyn to the study of the problems of cosmical astronomy.

A very interesting account of the Geodetic Survey of South Africa is supplemented by an appendix by Dr. Wilhelm Bahn (translated from the Beiträge zu Geophysik) on the South African arc of meridian. Arcs of meridian were measured by Lacaille and Maclear, and between 1859 and I862 the triangulation of the southern coast of Cape Colony was taken in hand. Soon after Gill's appointment, he pointed out to Sir Bartle Frere the advantage to be gained by a comprehensive survey, and recommended a gridiron system of chains of principal triangulation extending over the Cape Colony, the Orange Free State, Natal, and the Transvaal. This work has been carried out under the direction of Sir William Morris in the field, with Sir David Gill as scientific adviser, who kept constantly in view the service to geodesy which would be derived from the measurement of a large arc on the 3oth meridian of east longitude. This was afterwards continued through Rhodesia, and the extreme arc measured extends over nearly $22^{\circ}$ from $31^{\circ} 36^{\prime} \mathrm{S}$. lat. to $9^{\circ} 4 \mathrm{I}^{\prime} \mathrm{S}$. lat. There are six base-line determinations along the arc, and sixty determinations of astronomical latitude. The measures of the South African arc of meridian indicate a somewhat larger terrestrial spheroid than that of Clarke, and are in accordance with the results obtained by Hayford in the United States. The extension of this arc to join the Egyptian arc, and the connection round the eastern end of the Mediterranean to join the Russian arc measured by Struve is of great scientific importance, and, as Sir David Gill points out, offers no very formidable difficulty if international cooperation is secured.

In this article only portions of the volume have been touched upon. Sir David Gill is to be congratulated on the production of a work the historical and narrative portions of which are of interest to all men of science, while the technical portions are of the greatest value to astronomers. He may be assured that others will find guidance and inspiration in this history of the Cape $\mathrm{Ob}$ servatory, as he himself did in Struve's account of Pulkova.

F. W. Dyson.

\section{SCIENTIFIC METHODS OF IDENTIFYING PICTURES.}

UP to the present time the identification of works of art has been entrusted entirely to the art expert, who brings to bear upon the problem his wide experience and artistic training; and, in addition, it is probable that among those engaged in buying and selling pictures, many devices kept as trade secrets are useful in identifying pictures. While not for a moment denying that the final word should lie with the trained art expert, it is of interest to see how far scientific methods can be brought to bear upon this problem. The first step in this direction is a careful study of the history of pigments. By the examination of ancient documents, such as the illuminated manuscripts of the monks, Venetian Ducali, and the Coram Rege Rolls, it has been possible to plan out the history of pigments probably with sufficient accuracy for practical purposes, and to fix the dates approximately of certain pigments which appear and others that disappear from the artist's palette. This method, where applicable, may be regarded as infallible, as the presence of a pigment of a date more modern than the date at which the picture is supposed to be painted proves either forgery or repainting, and a carefui microscopic examination make it quite possible to tell whether the picture has been repainted or not.

This, however, does not settle the authorship NO. 2307 , VOL. 92] 